\title{
Enhancement of Teliospore Germination in Wheat- and Wild Grass-Infecting Species of Tilletia on Activated Charcoal Medium
}

\author{
María L. Boyd and Lori M. Carris
}

Department of Plant Pathology, Washington State University, Pullman 99164-6430.

Accepted for publication 3 December 1997.

\begin{abstract}
Boyd, M. L., and Carris, L. M. 1998. Enhancement of teliospore germination in wheat- and wild grass-infecting species of Tilletia on activated charcoal medium. Phytopathology 88:260-264.

The effect of activated charcoal as an amendment to water agar medium on teliospore germination was analyzed for two species of wheat-infecting bunts, Tilletia controversa and T. tritici, and two related wildgrass infecting species, T. bromi and T. fusca. Final percentages of teliospore germination, area under the germination progress curves (AUGPC), and a standardized AUGPC (SAUGPC) on carbon agar and water agar

the final germination percentage of teliospores, AUGPC, and SAUGPC when compared with water agar (WA) for all taxa under study. Additionally, CA reduced significantly the incubation (i.e., lag) period when compared with WA for teliospores of $T$. bromi, T. controversa, and $T$. fusca. Bovine serum albumin and polyvinyl pyrrolidone were used as alternative chemical adsorbent amendments to WA to establish the role of activated charcoal in the medium. Only media amended with bovine serum albumin and activated charcoal improved the final germination percentage of all taxa. Polyvinyl pyrrolidone was not significantly better than water agar.
\end{abstract} were compared among strains. Carbon agar (CA) significantly increased
The in vitro germination of teliospores of the smuts and bunts (Basidiomycota; Ustilaginales) is critical for the study of these plant pathogenic fungi. Characteristics of teliospore germination provide the basis for dividing the Ustilaginales into the Ustilaginaceae and Tilletiaceae and also for delimiting genera and species within the families. The number, shape, type, and nuclear condition of the sporidia produced from germinated teliospores are frequently used to establish the identity of species $(8,9,12)$. Teliospores of many genera in the smuts and bunts germinate poorly on artificial media, making their classification into families uncertain. Recently, the application of molecular markers for the identification of smut fungi has been used, requiring DNA extracted either from large numbers of teliospores (11) or from mycelium or sporidia isolated from germinated teliospores and increased on artificial media $(4,10,23)$.

The difficulty in germinating teliospores of Tilletia spp. is evident in the length of the incubation time needed for germination and subsequent colony production. Poor germination is a common problem among teliospores from old collections or collections stored under less than optimal conditions (13). Teliospores of the wheat common bunt species $T$. tritici and $T$. laevis germinate best at 14 to $16^{\circ} \mathrm{C}$ and require an incubation period of less than 10 days $(14,15)$. In contrast, teliospores of the dwarf bunt fungus $T$. controversa require 3 to 6 weeks at $5^{\circ} \mathrm{C}(14,15)$. Germination requirements of the wild grass-infecting species $T$. fusca and $T$. bromi are 2 to 4 weeks at $5^{\circ} \mathrm{C}$, intermediate to the wheat bunts $(13,20)$. The teliospores of many Ustilago species, in contrast, germinate in less than $24 \mathrm{~h}$ on artificial medium, as exemplified by the corn smut fungus, U. zeae (3).

Minimal media are generally used to germinate teliospores of Tilletia species. Two percent water agar (WA) is the most com-

Corresponding author: L. M. Carris; E-mail address: carris@mail.wsu.edu

Publication no. P-1998-0120-01R

(C) 1998 The American Phytopathological Society mon medium used, but soil extract agar (SEA) and two chemically defined media, T-19 and T-19m (26), have also been used. Media amended with charcoal have been used successfully to improve growth of Phytophthora infestans (21), the heterokaryon of Rhizoctonia solani (5), and as a mating medium for $U$. hordei (19) and $U$. zeae (7). Keil (16) demonstrated nutrient medium amended with activated charcoal improved the germination level of $T$. tritici, U. avenae, U. tritici, U. hordei, and Helminthosporium gramineum. His study did not directly compare the charcoal medium with WA. The purpose of this study was to determine if the addition of activated charcoal to $2 \%$ WA affects the germination of teliospores in Tilletia spp. Germination of recent and old collections of wheat-infecting species and related wild grass-infecting species of Tilletia was compared. In addition, the function of activated charcoal in the medium was examined.

\section{MATERIALS AND METHODS}

Isolates and media. Three collections of each taxon and host combination were used (Table 1). All collections were less than 15 years old for this part of the study. WA (2\%; Sigma Chemical Co., St. Louis) was made according to standard practices. Carbon agar (CA) was made by addition of $1 \%$ activated charcoal (carbon; B \& A, Morristown, NJ) to $2 \%$ WA prior to autoclaving.

Intact sori were removed from each collection and placed in microcentrifuge tubes. The number of sori used per collection depended on sorus size and abundance of available material. The sori were crushed in a drop of sterile distilled water with a glass rod. Teliospores were surface-sterilized with a $5 \%$ commercial bleach (sodium hypochlorite) solution and rinsed twice with sterile distilled water. Approximately $0.2 \mathrm{ml}$ of a teliospore suspension was streaked on three 60 - by $15-\mathrm{mm}$ petri plates each of WA and CA. All plates were incubated at $6^{\circ} \mathrm{C}$ with $8 \mathrm{~h}$ of light, with the exception of T. tritici plates, which were incubated at $15^{\circ} \mathrm{C}$.

Effect of activated charcoal. Germination percentages were determined based on counts made from five $0.75-\mathrm{cm}$-diameter 
areas in which at least 20 teliospores were visible in each petri plate. The agar in each plate was marked with a core borer and labeled so that subsequent readings could be made from the same area. Plates were examined every 2 days for teliospore germination using a stereoscope (20 to $30 \times$ magnification) with reflected light. The presence of primary sporidia was considered an essential criterion for teliospore germination. Germination was evaluated daily from germination of the first teliospore within the marked area, until no further reliable assessments could be made due to the presence of germinated primary sporidia, secondary sporidia, and mycelium in the marked areas.

The five sections within a plate represented subsamples, and each plate was considered an experimental unit. Three replications were arranged in randomized complete block design. To use all the germination data recorded through time, the area under the germination progress curve (AUGPC) was determined according to Campbell and Madden (6). AUGPC values were determined for each of the sections on a plate for every treatment. A standardized AUGPC (SAUGPC) was derived by dividing the AUGPC value by the number of readings or days that the germination was assessed. The lag period was recorded as the number of days from the day of plating (day 0) to the first day of germination. The main effects analyzed for each treatment were final germination percentage, AUGPC, and SAUGPC. Data were analyzed using the GLM procedure in SAS (SAS Institute, Inc., Cary, NC). Student's $t$ test was performed for data from each host and taxon to establish effect of media on germination.

Effect of media on teliospore germination in old collections. Twenty-six collections stored under herbarium conditions for 30 to 48 years (Table 2) were surface-sterilized and streaked onto WA and CA. Plates were examined for germination over a period of 2 months. Single sporidial isolates were made from germinated teliospores using a Chambers Micromanipulator (E. Leitz, Inc., Rockleigh, NJ) and grown at $15^{\circ} \mathrm{C}$ on potato sucrose agar to assure that the sporidia produced from these collections were viable and capable of producing mycelium.

Effect of media with other adsorbents. Teliospore germination on Noble's WA (2\%; Difco Laboratories, Detroit) and WA

TABLE 1. Collections of Tilletia spp. used in studies designated by isolate number, geographic origin, date collected, and host origin

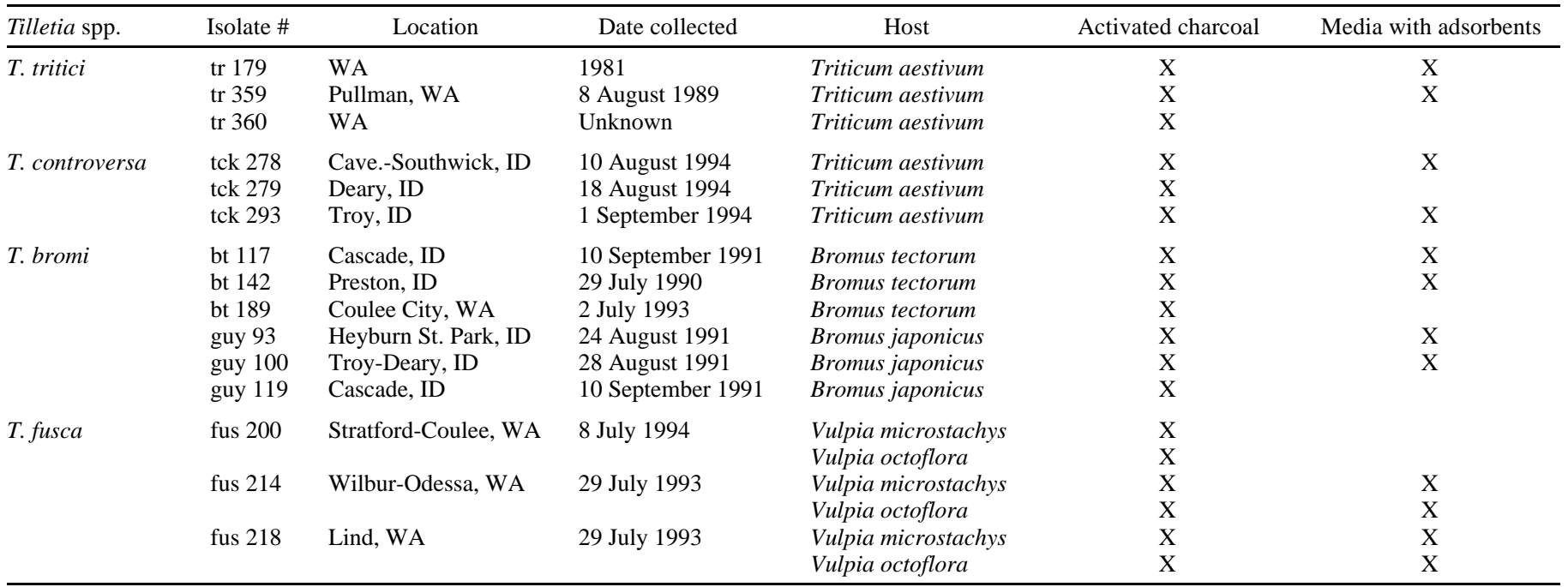

TABLE 2. Herbarium specimens used in study by isolate number, date collected, and host

\begin{tabular}{|c|c|c|c|c|}
\hline Species & Isolate \# & Location & Date collected & Host \\
\hline Tilletia sp. & t 361 & Italy & 1948 & Triticum aestivum \\
\hline \multirow[t]{13}{*}{ T. bromi } & M 1121 & Yellowstone, WY & 1956 & Bromus tectorum \\
\hline & M 1134 & Pullman, WA & 1956 & Bromus sterilis \\
\hline & M 1188 & Huntington, UT & 1957 & Bromus tectorum \\
\hline & M 1183 & Wallsbutty, UT & 1957 & Bromus japonicus \\
\hline & M 1141 & Battle Mtn. State Park, OR & 1957 & Bromus brizaeformis \\
\hline & WSP 58618 & Mt. Cache Nat. Forest, UT & 1967 & Bromus tectorum \\
\hline & WSP 66412 & Romania & 1966 & Bromus mollis \\
\hline & WSP 44349 & Yellowstone, WY & 1956 & Bromus tectorum \\
\hline & WSP 44202 & Logan, UT & 1955 & Bromus japonicus \\
\hline & WSP 44203 & Elgin, OR & 1955 & Bromus japonicus \\
\hline & WSP 44204 & Bozeman, MT & 1954 & Bromus japonicus \\
\hline & WSP 44198 & Elgin, $\mathrm{OR}$ & 1954 & Bromus brizaeformis \\
\hline & WSP 49570 & Farmington, WY & 1959 & Bromus brizaeformis \\
\hline \multirow{3}{*}{ T. fusca } & WSP 44208 & Ritzville, WA & 1955 & Vulpia microstachys \\
\hline & WSP 58339 & Pixley, CA & 1967 & Vulpia microstachys \\
\hline & WSP 44205 & Boise, ID & 1955 & Vulpia microstachys \\
\hline T. tritici & $\operatorname{tr} 362$ & Corvallis, OR & 1951 & Festuca rubra \\
\hline
\end{tabular}


TABLE 3. Means and $P$ values for effect of activated charcoal on Tilletia species

\begin{tabular}{|c|c|c|c|c|}
\hline \multirow[b]{2}{*}{ Species } & \multicolumn{2}{|c|}{ Percent of germination } & \multicolumn{2}{|c|}{ SAUGPC $^{\mathrm{a}}$} \\
\hline & Mean & $P$ value & Mean & $P$ value \\
\hline T. bromi & $\begin{aligned} \mathrm{CA}^{\mathrm{b}} & =30 \\
\mathrm{WA}^{\mathrm{c}} & =11\end{aligned}$ & 0.0001 & $\begin{aligned} \mathrm{CA} & =14 \\
\mathrm{WA} & =5\end{aligned}$ & 0.0001 \\
\hline T. controversa & $\begin{aligned} \mathrm{CA} & =20 \\
\mathrm{WA} & =0.4\end{aligned}$ & 0.0069 & $\begin{aligned} \mathrm{CA} & =7 \\
\mathrm{WA} & =0.03\end{aligned}$ & 0.0055 \\
\hline T. fusca & $\begin{aligned} \mathrm{CA} & =44 \\
\mathrm{WA} & =12\end{aligned}$ & 0.0001 & $\begin{aligned} \mathrm{CA} & =21 \\
\mathrm{WA} & =6\end{aligned}$ & 0.0001 \\
\hline T. tritici & $\begin{aligned} \mathrm{CA} & =39 \\
\mathrm{WA} & =25\end{aligned}$ & 0.0212 & $\begin{aligned} \mathrm{CA} & =12 \\
\mathrm{WA} & =7\end{aligned}$ & 0.0244 \\
\hline
\end{tabular}

${ }^{a}$ SAUGPC $=$ standardized area under germination progress curve.

${ }^{\mathrm{b}} \mathrm{CA}=$ carbon agar.

${ }^{\mathrm{c}} \mathrm{WA}=$ water agar. amended with bovine serum albumin (BSA; Sigma Chemical Co.) and polyvinyl pyrrolidone (PVP; Sigma Chemical Co.) were compared with germination on CA and WA. Water agar was amended either with $0.5 \% \mathrm{wt} / \mathrm{vol} \mathrm{BSA}$ or $0.5 \% \mathrm{wt} / \mathrm{vol} \mathrm{PVP}$ as described in Stone et al. (24). Teliospores were surface-sterilized and streaked on media as previously described. Two collections per host/taxon combination were used, with two replications and two subsamples per treatment. Final percentage of germination was analyzed using the GLM procedure, and treatment mean comparisons were made with Fisher's protected least significant difference (LSD; $P \leq 0.05$ ).

\section{RESULTS AND DISCUSSION}

Use of CA increased the final percent germination, the AUGPC, and the SAUGPC for all collections. AUGPC and SAUGPC were
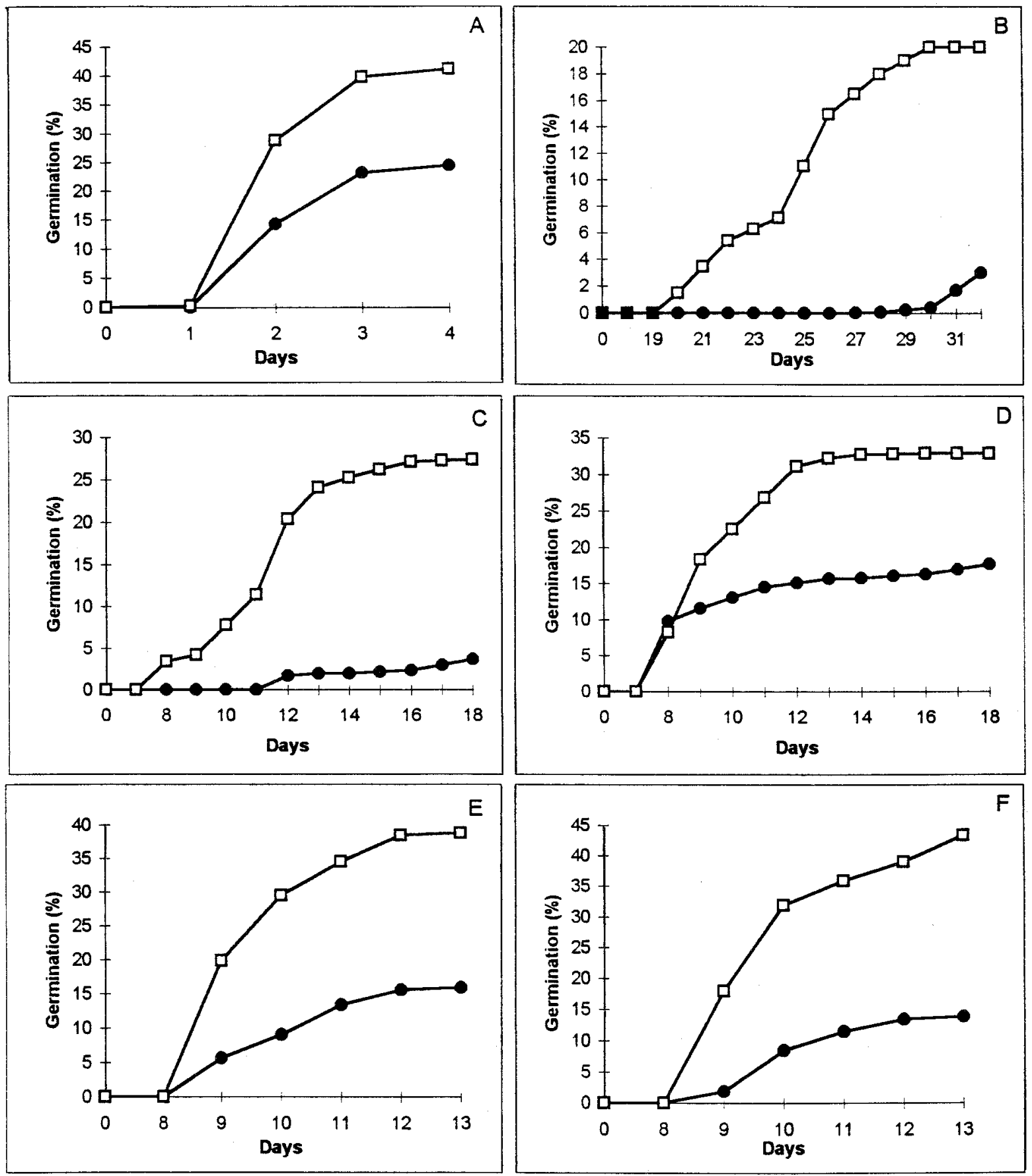

Fig. 1. Teliospore germination progress curves for A, Tilletia tritici; $\mathbf{B}$, T. controversa; $\mathbf{C}$, T. bromi on Bromus japonicus; $\mathbf{D}$, T. bromi on Bromus tectorum; E, T. fusca on Vulpia microstachys; and $\mathbf{F}$, T. fusca on Vulpia octoflora $\bullet=$ water agar and $\square=$ carbon agar. 
similar in assessing the significance of treatments; therefore, only SAUGPC values are presented (Table 3, Figs. 1 and 2). The final teliospore germination was increased on the amended medium an average of $26 \%$ for $T$. fusca, $19 \%$ for T. bromi, $17 \%$ for T. controversa, and $15 \%$ for $T$. tritici isolates. There were no differences in final germination percentage, AUGPC, or SAUGPC between isolates within a taxon, replication, or subsample. The addition of charcoal reduced the lag period for all taxa except $T$. tritici. The lag period was reduced in $T$. bromi from 14 to 10 days $(P=$ $0.0001)$, in $T$. controversa from 29 to 23 days $(P=0.0009)$, and in T. fusca from 10 to 9 days $(P=0.0001)$.

Of the 25 old collections evaluated, teliospores from only two species germinated and produced primary sporidia on CA: T. controversa (WSP 55699) and T. bromi (WSP 58619, 58607, 49570, 51889 , and M1121). Primary sporidia from three of these collections (T. controversa WSP 55699 and T. bromi WSP 58619 and 58607) germinated and continued growing to produce colonies. Two additional isolates, WSP 44203 (T. bromi) and t 361 (Tilletia sp.) produced promycelia, but not primary sporidia. The oldest collection grown successfully to a mycelial stage was 33 years old (T. bromi, WSP 58607). Teliospores of only one isolate (WSP 51889) germinated on WA, but the primary sporidia did not produce colonies.

Media with activated charcoal and BSA improved $(P=0.0001)$ the germination in all taxa when compared with Noble's agar, WA, or PVP. CA improved the mean germination (67\%) compared with BSA $(47 \%)$ for isolates of $T$. fusca $(P=0.0076)$. Mean germination of teliospores was similar on CA and BSA for T. bromi (56 and 48\%), T. controversa (4.5 and 4.6\%), or T. tritici (31 and $32 \%$ ), respectively. Noble's WA, WA, and PVP did not differ in their effect on the mean germination of these taxa: T. bromi (26, 15 , and $21 \%)$, T. controversa $(0,0$, and $0 \%), T$. fusca $(24,21$, and $26 \%$ ), and $T$. tritici $(7,8$, and $9 \%)$, respectively.

The improved germination on CA was most pronounced in $T$. controversa, a species characterized by low germination, longer lag periods prior to germination, and lower optimum germination temperatures relative to $T$. tritici. The germination of $T$. controversa on CA, although only $20 \%$, represents a very substantial increase over the near-lack of germination that occurred on WA. The length of the incubation period required for teliospore germination in Tilletia spp. has been attributed to the presence of endogenous and exogenous inhibitors (25). Self-inhibitors were identified and characterized for species of Tilletia (25) as well as for species of rusts $(18,22)$. Trione and Ross $(25)$ reported that teliospores of $T$. controversa had higher levels of exogenous in-
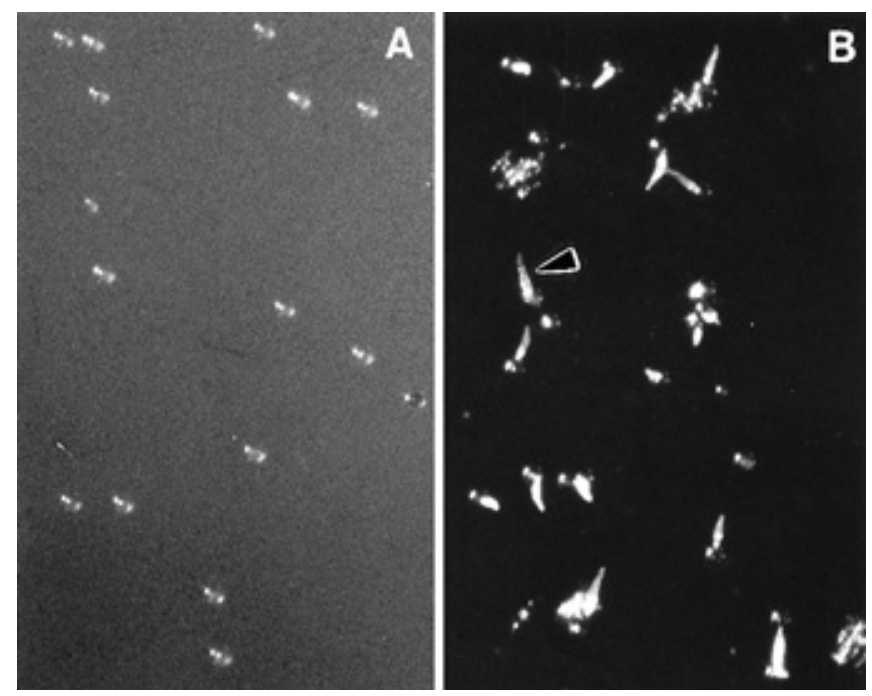

Fig. 2. Teliospores of Tilletia bromi from Bromus japonicus (guy 119) after 15 days of incubation on $\mathbf{A}$, water agar and B, carbon agar. Arrow shows cluster of primary sporidia. hibitors (lipids, fatty acid mixtures, and linoleic acids) than the teliospores of $T$. tritici. These inhibitors could delay or prevent teliospore germination in the sorus in nature and provide for longer survival of $T$. controversa in the soil and may account for the longer incubation period required for teliospore germination for $T$. controversa relative to that of $T$. tritici. Exogenous inhibitors present in $T$. controversa may somehow be inactivated or unavailable on activated charcoal. Species with the highest levels of inhibitory compounds are likely to show the greatest germination response on $\mathrm{CA}$.

The germination requirements for the wheat bunt species of Tilletia and related wild grass species (i.e., T. bromi and T. fusca) were compared in previous studies $(13,15,20)$. Meiners and Waldher (20) and Guillemette (13) showed that soil extract agar (SEA) was a better medium for the germination of Tilletia. Guillemette (13) showed that teliospore germination overall was better on SEA than on WA, but the results were dependent upon the isolate and type of soil used for SEA. The germination of some isolates was not improved with the use of SEA (13).

Most investigators who have used activated charcoal as an amendment for media speculate that it functions as an adsorbent of some unknown compound present in the media that prevents growth, mating, or proper development of organisms $(2,5,7,19,21)$. Stone et al. (24) used $0.025 \%$ activated charcoal to germinate ascospores of Anisogramma anomala. They used several different adsorbents to show that an unidentified substance, possibly an inhibitor, was preventing the germination of spores. Activated charcoal has been reported to remove substances inhibitory for the growth of tissue culture $(2,17)$, bacterial cultures (1), and fungal cultures $(5,7,18,19,21,24)$. The results of our study suggest that the teliospore germination of wheat- and wild grass-infecting species of Tilletia is inhibited by a substance that is adsorbed by both activated charcoal and BSA, but not by PVP. Activated charcoaland BSA-amended media equally increased the percentage of germination of three of the Tilletia species in the study. Only in the case of $T$. fusca was CA significantly better. The ease of preparation of CA over BSA makes it a better option for standard laboratory use. Kohlenbach and Wernicke (17) showed that substances in the agar were inhibiting tissue culture of plants, and that reduction of the agar concentration or use of purified forms of agar (Noble's agar) yielded significantly better growth. We did not find a significant difference in teliospore germination using Noble's agar versus a less purified form, which indicates that any inhibitor present is probably from the bunt balls or the teliospores and not the agar.

The method by which herbarium specimens are kept may have an influence on the germinability of teliospores $(13,20)$. Teliospore viability in collections subject to heat or cold treatments (oven-drying or freezing), desiccants, or compounds for insect control, as well as temperature and humidity fluctuations, may be adversely affected. The ability to germinate teliospores from collections up to 33 years old with the use of CA expands the material available for analysis in this genus. Molecular and cytological studies have proven a valuable complement to teliospore morphology in delimiting discrete taxa in this group of fungi $(4,8,9,12)$. Obtaining adequate amounts of total DNA from Tilletia species requires germinating teliospores, isolating sporidia, growing colonies on agar, and growing shake cultures to obtain an adequate amount of mycelium for the extraction procedures $(0.2$ to $2.0 \mathrm{~g}$ of lyophilized mycelium; 4,10,23). The improvement in teliospore final germination percentage and the reduction of the lag period will reduce the amount of time needed to go from teliospores to extracted DNA, facilitating the use of larger numbers of isolates in the study of this genus.

\section{ACKNOWLEDGMENTS}

PPNS 0263, College of Agriculture and Home Economics Research Center Project 3837, Washington State University, Pullman. This work 
was supported by USDA-CSRS grant 94-37303-0731. We thank D. Johnson, W. Kaiser, and J. D. Rogers for reviewing the manuscript; P. M. Gray for technical assistance; two anonymous reviewers for suggestions that greatly improved the final text; and J. Miller for assistance with the program SAS.

\section{LITERATURE CITED}

1. Alwen, J., and Smith, D. G. 1967. A medium to suppress the swarming of Proteus species. J. Appl. Bacteriol. 30:389-394.

2. Anagnostakis, S. L. 1974. Haploid plants from anthers of tobaccoEnhancement with charcoal. Planta (Heidelb.) 115:281-283.

3. Banuett, F. 1991. Life cycle determinants of the plant pathogen Ustilago maydis. Pages 217-233 in: More Gene Manipulations in Fungi. J. W. Bennett and L. L. Lasure, eds. Academic Press, Inc., San Diego, CA.

4. Boyd, M. L., and Carris, L. M. 1997. Molecular relationships among varieties of the Tilletia fusca (T. bromi) complex and related species. Mycol. Res. 101:269-277.

5. Butler, E. E., and Bolkan, H. 1973. A medium for heterokaryon formation in Rhizoctonia solani. Phytopathology 63:542-543.

6. Campbell, C. L., and Madden, L. V. 1990. Introduction to Plant Disease Epidemiology. John Wiley \& Sons, Inc., New York.

7. Day, P. R., and Anagnostakis, S. L. 1971. Corn smut dikaryon in culture. Nat. New Biol. 231:19-20.

8. Durán, R. 1980. Tilletia aegopogonis, a homo-heterothallic bunt fungus. Phytopathology 70:528-533.

9. Durán, R. 1983. Tilletia lycuroides, another homo-heterothallic bunt fungus. Mycologia 75:974-976.

10. Ferreira, M. A. S. V., Tooley, P. W., Hatziloukas, E., Castro, C., and Schaad, N. W. 1996. Isolation of a species-specific mitochondrial DNA sequence for identification of Tilletia indica, the Karnal bunt of wheat fungus. Appl. Environ. Microbiol. 62:87-93.

11. Gang, D. R., and Darrell, J. 1995. Preparation of genomic DNA for RAPD analysis from thick-walled dormant teliospores of Tilletia species. BioTechniques 19:93-97.

12. Guillemette, M. K. 1988. Tilletia togwatii, a new bunt species from Poa reflexa. Mycologia 80:273-285.

13. Guillemette, M. K. 1989. Factors influencing teliospore germination in Tilletia fusca. Phytopathology 79:246-252.

14. Hoffmann, J. A. 1982. Bunt of wheat. Plant Dis. 66:979-986.

15. Holton, C. S., Hoffmann, J. A., and Durán, R. 1968. Variation in the smut fungi. Annu. Rev. Phytopathol. 6:213-242.

16. Keil, J. 1940. Ein neuer Nährboden zu Keimversuchen mit Getreidepilzsporen. (Ustilago avenae, U. tritici, U. hordei, Tilletia tritici and Helminthosporium gramineum). Arch. Mikrobiol. 11:85-88.

17. Kohlenbach, H. W., and Wernicke, W. 1978. Investigations on the inhibitory effect of agar and the function of active carbon in anther culture. Z. Pflanzenphysiol. Bd. 86:463-472.

18. Macko, V., Trione, E. J., and Young, S. A. 1977. Identification of the germination self-inhibitor from uredospores of Puccinia striiformis. Phytopathology 67:1473-1474.

19. Martinez-Espinosa, A. D., Dugan, K. J., Bjarko, M. E., and Sherwood, J. E. 1992. Improved media for testing the mating reaction and genetic complementation of Ustilago hordei. Can. J. Bot. 70:788-793.

20. Meiners, J. P., and Waldher, J. T. 1959. Factors affecting spore germination of twelve species of Tilletia from cereals and grasses. Phytopathology 49:724-728.

21. Parmentier, G. 1970. L'incorporacion de charbon actif aux milieux de cuture de Phytophthora infestans. Parasitica 26:31-40.

22. Pritchard, N. J., and Bell, A. A. 1967. Relative activity of germination inhibitors from spores of rust and smut fungi. Phytopathology 67:932-934.

23. Smith, O. P., Peterson, G. L., Beck, R. J., Schaad, N. W., and Bonde, M. R. 1996. Development of a PCR-based method for identification of Tilletia indica, causal agent of Karnal bunt of wheat. Phytopathology 86: 115-122.

24. Stone, J. K., Pinkerton, J. N., and Johnson, K. B. 1994. Axenic culture of Anisogramma anomala: Evidence for self-inhibition of ascospore growth. Mycologia 86:674-683.

25. Trione, E. J., and Ross, W. D. 1988. Lipids as bioregulators of teliospore germination and sporidial formation in the wheat bunt fungi, Tilletia species. Mycologia 80:38-45.

26. Tuite, J. 1974. Plant Pathological Methods. Burgess Publishing Co., Minneapolis, MN. 